\title{
KEBIJAKAN PROGRESIF DALAM PELAKSANAAN PP NO. 24 TAHUN 1997 TERHADAP PEMBERIAN SERTIFIKAT SEBAGAI ALAS HAK YANG SAH
}

\author{
Wibowo Murti Samadi \\ Shinta Rukmi B
}

\begin{abstract}
ABSTRAK
Tujuan Penelitian. Ingin mengkaji dan menganalisis kebijakan progresif dalam pelaksanaan PP No. 24 tahun 1997 terhadap pemberian sertifikat sebagai alas hak yang sah dan mengkaji dan menganalisis faktor pendukung dan penghambat implementasi kebijakan progresif tersebut. Latar Belakang. Kebijakan Negara dalam menjalankan amanah PP No.24 Tahun 1997, Yakni melakukan proses pendaftaran tanah secara lengkap dengan menganulir hakekat konversi bidang pendaftaran tanah yang seharusnya dibeikan waktu 20 tahun dari UUPA No.5 Tahn 1960 sampai dengan Tahun 1980. Namun negara mempunyai otoritas mengambil kebijakan progresif dengan masih menerima terhadap pendaftaran tanah yang belum mempunyai alat bukti sertifikat.

Hasil Penelitian. Pelaksanaan pendaftaran tanah sistem lengkap merupakan kebijakan progresif negara melalui PP 24 Tahun 1997 bahwa pemberian kepastian hukum terhadap hak atas tanah kepada masyarakat dilakukan dalam rangka tertib administrasi dan rasa nyaman atas alat bukti kepemilikan yang dipegang oleh pemilik tanah. Hal ini merupakan kebijakan negara walaupun aturan konversi bahwa sejak 24 September 1960 (UUPA) sampai dengan tahun 1980 telah dilakukan ketentuan konversi setiap pemilik hak atas tanah harus melakukan penyesuaian hak atas tanah yang tercantum dalam UUPA. Namun, sampai dengan saat ini negara masih memberlakukan proses pendaftaran tanah progresif (PTSL) sehingga dapat disimpulkan negara mempunyai kebijakan progresif yang dilakukan menurut PP 24 Tahun 1990. Faktor-faktor yang menjadi kendala dalam pelaksanaan PTSL di Kabupaten Boyolali, antara lain: a. Tingkat pendidikan masyarakat yang masih sangat rendah, menyebabkan tidak semua komponen masyarakat memahami dan memiliki daya tanggap yang cepat terkait pelaksanaan PTSL; b. Pemohon PTSL susah untuk dihadirkan pada saat kegiatan pengukuran karena adanya beberapa kesibukan. c. Pemohon tidak melakukan pemasangan tanda batas dengan beberapa alasan, baik itu karena belum ada waktu yang tepat ataupun masih terjadi sengketa dengan pemilik tanah yang berbatasan hal ini menyebabkan penundaan kegiatan pelaksanaan. d. Kelengkapan pengumpulan syarat administrasi oleh para pemohon.

Kata kunci : kebijakan progresif, alat bukti sertifikat
\end{abstract}

\section{ABSTRACT}

Purpose: to examine and analyze the progressive policy in implementing PP No. 24 tahun 1997 toward the giving certificate of legal right and to examine and analyze the supporting and inhibiting factors in implementing the progressive policy. Background. The state policy in implementing PP No.24 Tahun 1997, is processing registration of land completely and eliminating the conversion nature of land registration division given in 20 years from UUPA No.5 Tahn 1960 to 1980. Yet, state has authority to take progressive policy by accepting land registration having no certificate evidence.

Result. The implementation of complete land registration is the state progressive policy through PP 24 Tahun 1997 that giving law certainty of right of land to the public is done to be orderly administration and comfortable of the ownership certificate held by the land owner. It is a state policy although the conversion regulation states that from 24 September 1960 (UUPA) to 1980 it has been conducted conversion regulation that every land owner must do adapt right of land stated in UUPA. However, till present time, the state still hold progressive land registration process so that it can be concluded that the state has progressive policy done in accordance to PP 24 Tahun 1990. Factors inhibiting the implementation of the progressive land registration process in Kabupaten Boyolali are: a. very low level of education, causing not all community understand and respond rapidly the implementation of progressive land registration process; $b$. the appellant of progressive land registration process is difficult to attend the measurement activity because of business. c. appellant do not attach border sign of several reasons, such as there is no proper time and the problem between the owner of the side land causing delay of the implementation. d. the complete submission of administration requirement by the appellant.

Keywords : progressive policy, certificate evident 


\section{A. Latar Belakang}

Atas dasar ketentuan di atas, perlu adanya tindakan pemerintah serta kesadaran masyarakat dalam rangka pendataan tanah demi terwujudkan tertib administrasi, tertib hukum dan memenuhi tuntutan masyarakat Indonesia. Penyelenggaraan pendaftaran tanah akan menghasilkan suatu produk akhir yaitu berupa sertifikat sebagai tanda bukti kepemilikan hakatas tanah. Namun dalam pelaksanaannya, pasti ada hambatan, baik dalam pelaksanaan administrasi maupun dari masyarakat itu sendiri. Masyarakat masih ada yang belum begitu mengerti akan pentingnya suatu pendataan tanah. Pemegang hak atau tanah berhak mendapatkan bukti otentik yang berkekuatan hukum tentang kepemilikan tanahnya dari lembaga yang berwenang, yaitu Badan Pertanahan Nasional.

Kebijakan Negara dalam menjalankan amanah PP No.24 Tahun 1997, Yakni melakukan proses pendaftaran tanah secara lengkap dengan menganulir hakekat konversi bidang pendaftaran tanah yang seharusnya dibeikan waktu 20 tahun dari UUPA No.5 Tahn 1960 sampai dengan Tahun 1980. Namun negara mempunyai otoritas mengambil kebijakan progresif dengan masih menerima terhadap pendaftaran tanah yang belum mempunyai alat bukti sertifikat tetapi masih berupa Petuk,
Girik, Pipil dan seterusnya. Langkah progresif ini mendatangkan rasa aman dalam pencatatan hak atas tanah dari desa ke desa di seluruh wilayah negara Republik Indonesia.

\section{B. Rumusan Masalah}

Berdasarkan latar belakang tersebut dapat dirumuskan permasalahan penelitian sebagai berikut :

1. Bagaimanakah kebijakan progresif dalam pelaksanaan pp no.24 tahun 1997 terhadap pemberian sertifikat sebagai alas hak yang sah?

2. Apakah faktor pendukung dan penghambat implementasi kebijakan progresif tersebut?

\section{Tujuan Penelitian}

1. Ingin mengkaji dan menganalisis kebijakan progresif dalam pelaksanaan PP No. 24 tahun 1997 terhadap pemberian sertifikat sebagai alas hak yang sah.

2. Mengkaji dan menganalisis faktor pendukung dan penghambat implementasi kebijakan progresif tersebut

\section{Metode Penelitian}

\section{Jenis Penelitian}

Didalam penelitian hukum, penelitian diskriftif dengan aspek yuridis normatif. Menurut pendapat Soetandyo ada lima konsep hukum (Setiono:2002):

a. Hukum adalah asas kepastian dan keadilan yang bersifat kodrati dan berlaku universal 
b. Hukum adalah norma-norma positif di dalam sistem perundang- undangan hukum nasional.

c. Hukum adalah apa yang diputuskan oleh Negara dalam memberikan aspek kesejahteraan dalam masyarakat melalui kebijakam progresif

d. Hukum adalah pola perilaku social yang terlembagakan, eksis sebagai variable sosial yang empirik.

e. Hukum adalah manifestasi makna- makna simbolik pada perilaku social sebagai tampak dalam interaksi antara mereka. Penelitian ini penelitian hukum normatif atau doktrinal, merupakan konsep yang ke dua yaitu Hukum adalah normanorma positif di dalam sistem perundang-undangan hukum nasional.

\section{Data Penelitian}

Data yang digunakan dalam penelitian ini adalah data primer dan data sekunder. Data primer diperoleh langsung dan lapangan dengan cara pengamatan. Namun data primer hanya sebagai pendukung dan data sekunder. Data sekunder merupakan data yang secara tidak langsung diperoleh peneliti atau data yang telah diolah oleh orang lain.

\section{E. Tinjauan Umum Tentang Pendaftaran Tanah}

\section{Pengertian Pendaftaran Tanah}

Pendaftaran tanah berasal dari kata Cadaster atau dalam bahasa belanda merupakan suatu istilah teknis untuk suatu record (rekaman) yang menerapkan mengenai luas, nilai dan kepemilikan terhadap suatu bidang tanah (AP. Parlindungan, 1988: 2) Menurut Pasal 1 Peraturan Pemerintah Nomor 24 Tahun 1997 disebutkan bahwa :

"Pendaftaran tanah adalah rangkaian kegiatan yang dilakukan oleh pemerintah secara terus menerus, berkesinambungan, dan teratur meliputi pengumpulan, pengolahan, pembukuan dan penyajian serta pemeliharaan data fisik dan data yuridis, dalam bentuk peta dan daftar, mengenai bidang-bidang tanah dan satuansatuan rumah susun, termasuk pemberian sertipikat sebagai surat tanda bukti haknya bagi bidangbidang tanah yang sudah ada haknya dan hak milik atas satuan rumah susun serta hak-hak tertentu yang membebaninya".

Budi Harsono (2003: 483) merumuskan pengertian pendaftaran tanah sebagai suatu rangkaian kegiatan yang dilakukan secara teratur dan terus menerus untuk mengumpulkan, mengolah, 
menyimpan dan menyajikan data tertentu mengenai bidang-bidang atau tanah-tanah tertentu yang ada di suatu wilayah tertentu dengan tujuan tertentu. Kegiatan pendaftaran tanah adalah kewajiban yang harus dilaksanakan oleh pemerintah secara terus menerus dalam rangka menginventarisasikan data-data berkenaan dengan hak-hak atas tanah menurut Undang-Undang Pokok Agraria dan Peraturan Pemerintah, sedangkan pendaftaran hak atas tanah merupakan kewajiban yang harus dilaksanakan oleh si pemegang hak atas tanah yang bersangkutan dan dilaksanakan secara terus menerus setiap ada peralihan hak-hak atas tanah tersebut menurut UndangUndang Pokok Agraria dan Peraturan Pemerintah guna mendapatkan sertifikat tanda bukti tanah yang kuat.

\section{F. Hasil dan Pembahasan}

1. Pelaksanaan Pendaftaran Hak Milik Atas Tanah Secara Sistematis Lengkap di Kabupaten Boyolali

Pelaksanaan Pendaftaran Tanah Sistematis Lengkap (PTSL) di Kantor Pertanahan Kabupaten Boyolali berdasarkan Peraturan Menteri Agraria dan Tata Ruang/Kepala Badan Pertanahan Nasional Republik Indonesia Nomor 6 Tahun 2018 tentang Pendaftaran Tanah Sistematis Lengkap, Kantor Pertanahan Kabupaten Boyolali mendapatkan jatah kuota sebesar 1500 sertifikat dari pengadaan program PTSL dan menargetkan 1500 bidang tanah terdaftar melalui program ini serta rencananya pada akhir jangka waktu kerja tahun 2018 pelaksanaan program PTSL di Kantor Pertanahan Kabupaten Boyolali ini dapat diselesaikan. Jangka waktu kerja oleh Kantor Pertanahan Kabupaten Boyolali dalam pelaksanaan pendaftaran tanah sistematis lengkap adalah 1 tahun anggaran yang dimulai dari awal bulan Januari sampai dengan akhir bulan Desember. Namun pada prakteknya pelaksanaan PTSL oleh Kantor Pertanahan Kabupaten Boyolali hanya 5 bulan kerja, yang dimulai pada bulan Maret dan selesai sampai dengan akhir bulan Juli 2018. Percepatan pelaksanaan yang tidak sesuai dengan rencana anggaran didasarkan karena masih banyaknya program-program daerah yang harus diselesaikan.

$$
\text { Berdasarkan Keputusan }
$$

Kepala Kantor Pertanahan Kabupaten Boyolali penetapan lokasi pelaksanaan pendaftaran tanah sistematis lengkap ini dilaksanakan pada Kecamatan Boyolali Kabupaten Boyolali. Hasil dari pelaksanaan PTSL oleh Kantor Pertanahan Kabupaten Boyolali dalam kurun waktu 5 bulan kerja telah mampu 
menghasilkan/merealisasikan

1500 bidang tanah yang terdaftar dapat tersertifikat. Pada saat pelaksanaan pensertifikatan masih ada sekitar 20\% yang bermasalah. Untuk tanah yang bermasalah sehingga mengindikasikan adanya pelambatan atau penundaan pelaksanaan PTSL, seperti sengketa maka pemohon yang terdaftar sebagai peserta PTSL akan diberi waktu kurang lebih selama 1 minggu untuk penyelesaian sengketa, karena dalam hal ini ketika Kantor Pertanahan Kabupaten Boyolali menemukan ada masalah seketika itu juga menghimbau agar pars pihak melakukan mediasi untuk menemukan kata sepakat sehingga pelaksanaan PTSL dapat dilanjutkan. Apabila tidak ada penyelesaian selama waktu yang telah diberikan maka pemohon akan dihapus dari daftar peserta yang mengikuti program PTSL, dan diganti dengan peserta lain dan desa yang sama. Penghapusan pemohon dari daftar peserta melalui pemberitahuan secara lisan baik langsung kepada pemohon ataupun melalui panitia desa. Untuk pemilihan peserta baru sebagai pemohon PTSL Kantor Pertanahan Kabupaten Boyolali menyerahkan wewenang secara penuh kepada panitia desa. Penghapusan status pemohon ini sebelumnya telah ada pemberitahuan pada saat kegiatan penyuluhan oleh Kantor Pertanahan Kabupaten Boyolali kepada segenap masyarakat, karena tanah yang dapat dijadikan objek PTSL adalah tanah yang tidak dalam sengketa, baik itu sengketa batas maupun sengketa kepemilikan.

\section{Hambatan-Hambatan}

Dalam

Pelaksanaan

Pendaftaran Hak Milik Atas

Tanah Secara Sistematis

Lengkap di Kabupaten Boyolali

Berdasarkan hasil penelitian yang telah dilakukan oleh peneliti terlihat adanya kendala-kendala dalam pelaksanaan pendaftaran tanah sistematis lengkap yang berimplikasi pada ketidakbenaran proses kegiatan pelaksanaan tersebut. Untuk mengatasi permasalahan yang terjadi masyarakat/pemohon PTSL, Pemerintah Daerah dan Kantor Pertanahan Kabupaten Boyolali harus dapat menjalin kerjasama dalam memperlancar proses pelaksanaannya. Usaha yang dapat dicapai menurut penulis diantaranya:

1) Dalam mengatasi permasalahan atau kendala seperti di atas khususnya dalam hal tingkat pemahaman masyarakat tentang PTSL ini, maka pihak 
Kantor Pertanahan Kabupaten Boyolali harus melakukan upaya penyelesaian dengan melakukan penyuluhan. Penyuluhan merupakan salah satu tahap dari pelaksanan PTSL, dan ada beberapa materi yang disampaikan, namun pihak Kantor Pertanahan Kabupaten Boyolali harus lebih menekankan atau lebih menjelaskan secara intensif dan konkrit tentang materi pembiayaan serta menekankan bahwa pelaksanaan program pensertifikatan ini sangat mudah untuk dilakukan. Penyampaian materi harus menggunakan bahasa yang sederhana dan lebih bagus jika penyuluhan menggunakan bahasa daerah Kabupaten Boyolali, karena rata-rata masyarakat Kabupaten Boyolali jarang yang dapat menanggapi dengan cepat penggunaan bahasa indonesia. Pada tahap penyuluhan ini harus diadakan sesi tanya jawab sampai dengan tidak adanya sesuatu yang membingungkan masyarakat. Selain itu Kantor Pertanahan Kabupaten Boyolali dapat menggunakan Brosur sebagai alat penyampaian informasi yang dapat dibawa kemana-mana oleh peserta/pemohon. Brosur dapat dibagikan kepada masyarakat Kandai Dua pada saat pelaksanaan penyuluhan dan disediakan di Kantor Pertanahan Kabupaten Boyolali.

\section{G. Kesimpulan}

Berdasarkan uraian diatas mengenai pelaksanaan pendaftaran tanah secara massal melalui Pendafataran Tanah Sistematis Lengkap (PTSL), maka dalam kesempatan ini, Penulis bermaksud untuk memberikan kesimpulan dari hasil penelitian dan pembahasan sebagai berikut:

1. Pelaksanaan pendaftaran tanah sistem lengkap merupakan kebijakan progresif negara melalui PP 24 Tahun 1997 bahwa pemberian kepastian hukum terhadap hak atas tanah kepada masyarakat dilakukan dalam rangka tertib administrasi dan rasa nyaman atas alat bukti kepemilikan yang dipegang oleh pemilik tanah. Hal ini merupakan kebijakan negara walaupun aturan konversi bahwa sejak 24 September 1960 (UUPA) sampai dengan tahun 1980 telah dilakukan ketentuan konversi setiap pemilik hak atas tanah harus melakukan penyesuaian hak atas tanah yang tercantum dalam UUPA. Namun, sampai dengan saat ini negara masih 
memberlakukan proses pendaftaran tanah progresif (PTSL) sehingga dapat disimpulkan negara mempunyai kebijakan progresif yang dilakukan menurut PP 24 Tahun 1990.

2. Faktor-faktor yang menjadi kendala dalam pelaksanaan PTSL di Kabupaten Boyolali, antara lain:

a. Tingkat pendidikan masyarakat yang masih sangat rendah, menyebabkan tidak semua komponen masyarakat memahami dan memiliki daya tanggap yang cepat terkait pelaksanaan PTSL.

b. Pemohon PTSL susah untuk dihadirkan pada saat kegiatan pengukuran karena adanya beberapa kesibukan.

c. Pemohon tidak melakukan pemasangan tanda batas dengan beberapa alasan, baik itu karena belum ada waktu yang tepat ataupun masih terjadi sengketa dengan pemilik tanah yang berbatasan hal ini menyebabkan penundaan kegiatan pelaksanaan.

d. Kelengkapan pengumpulan syarat administrasi oleh para pemohon

H. Saran

Setelah penulis mengambil beberapa kesimpulan dari data dan informasi yang telah di analisa, maka penulis akan mencoba untuk memberikan beberapa saran kepada Kantor Pertanahan Kabupaten Boyolali, Pemerintah Daerah maupun kepada masyarakat pada umumnya, agar pelaksanaan PTSL tahun yang akan datang dapat dilaksanakan dengan baik. Adapun saran-saran yang penulis kemukakan antaran lain:

1. Kantor Pertanahan Kabupaten Boyolali harus lebih meningkatkan kinerjanya tugasnya dalam memberikan informasi kepada masyarakat baik mengenai informasi pendaftaran tanah, informasi tentang syarat-syarat apa saja yang harus dimiliki pemohon. Sekaligus apabila ada biaya yang dibebankan pada peserta PTSL nantinya, hal tersebut agar tidak menjadi permasalahan dalam kelancaran pelaksanaannya.

2. Kantor Pertanahan Kabupaten Boyolali harus meningkatkan kerjasama dengan Pemerintah daerah dalam pelaksanaan kegiatan PTSL, agar dapat mengoptimalkan kegiatan daripada pelaksanaan tersebut. Maka hal ini harus dimulai dengan adanya bentuk koordinasi yang lebih antara Kantor Pertanahan 
\begin{tabular}{ll} 
Kabupaten & \multicolumn{2}{r}{ Boyolali, } \\
Pemerintah & Daerah dan \\
masyarakat. &
\end{tabular}

3. Untuk Kantor Desa, diperlukan bisa

mengkoordinasikan dengan warganya dengan cara melakukan pendekatan yang lebih intensif kepada warga yang mungkin masih kurang antusias dalam artian masih memiliki anggapan bahwa pelaksanaan PTSL ini susah.

Untuk warga desa yang akan mengikuti program PTSL tahun berikutnya, apabila adanya kegiatan penyuluhan yang dilakukan oleh Kantor Pertanahan Kabupaten Boyolali jika bisa datang tepat waktu dan tidak diwakilkan agar informasi yang disampaikan tidak setengahsetengah masuk dalam pemahaman dan sesuai apa yang disampaikan oleh Petugas, sehingga setelah dilakukannya penyuluhan masyarakat dapat melakukan persiapan.

\section{DAFTAR PUSTAKA}

A.P Parlindungan, 2009, Pendaftaran Tanah Di Indonesia (Berdasarkan PP No. 24 Tahun 1997) Dilengkapi Dengan Peraturan Jabatan Penjabat Pembuat Akta Tanah (PP No. 37 Tahun 1998), Bandung:Mandar Maju.
2009. Pendaftaran

Tanah di Indonesia. Bandung: Mandar Maju.

Ali Achmad Chomsah, 2002, Hukum Pertanahan (Pemberi Hak Atas Tanah Negara) Cerakan I, Yogyakarta, Prestasi Pustaka.

Bachtiar Effendie, 2005. Pendaftaran Tanah di Indonesia dan Peraturan Pelaksanaannya. Bandung : Penerbit Alumni.

Benny Bosu, 1999, Perkembangan Terbaru Sertipikat (Tanah, Tanggungan dan Condominium), PT Medisa, Jakarta.

Boedi Harsono. 2005. Hukum Agraria Indonesia Sejarah Pembentukan UndangUndang Pokok. Agraria Isi dan Pelaksanaannya. Jakarta: Djambatan.

Budi Winamo. 2007. Kebijakan Publik Teori Dan Proses, Jakarta : Media Pressindo. Efendi Perangin, 1986. Hukum Agraria Indonesia. Jakarta: CV. Rajawali. Prakoso.

Hasan Wargakusumah. 2008. Hukum Agraria I, Jakarta: PT. Gramedia Pustaka Utama.

Herman Hermit, 2004, Cara Memperoleh Sertipikat Tanah Hak Milik, Tanah Negara Dan Tanah Pemda, Teori dan Praktek Pendaftaran Tanah di Indonesia, Bandung: Mandar Maju.

Hermanes R, 1983, Pendaftaran Tanah di Indonesia, Yayasan Karya Dharma Institut Ilmu Pemerintahan, Jakarta.

Joko Widodo. 2010. Analisis Kebijakan Publik. Malang : Bayumedia Publishing. 
M. Irfan Islamy, 2009. Prinsipprinsip Perumusan Kebijaksanaan Negara. Jakarta: Bumi Aksara.

Mukhtar dan Widodo, Erna. 2009. Konstruksi Kearah Penelitian Dekriptif. Yogyakarta : Avyrouz.

Mukhtar dan Widodo, Erna. 2009. Konstruksi Kearah Penelitian Dekriptif. Yogyakarta : Avyrouz.

Sahnan. 2016. Hukum Agraria Indonesia, Malang: Setara Press.

Sahnan. 2016. Hukum Agraria Indonesia, Malang: Setara Press.

Soerjono Soekanto dan Sri Mamudji, 1995. Penelitian Hukum. Jakarta: Pustaka Sinar Harapan.

Soerjono Soekanto dan Sri Mamudji, 1995. Penelitian Hukum. Jakarta: Pustaka Sinar Harapan.

Sunaryo Basuki, 1998, Pendaftaran Tanah Berdasarkan Pasal 19 UUPA Jo. PP No. 24 Tahun 1997, Jakarta: Rineka Cipta.

Sunaryo Basuki, 1998, Pendaftaran Tanah Berdasarkan Pasal 19 UUPA Jo. PP No. 24 Tahun 1997, Jakarta: Rineka Cipta.

Supriadi, 2004, Hukum Agraria, Jakarta : Sinar Grafika.
Supriadi, 2004, Hukum Agraria, Jakarta : Sinar Grafika.

Yamin Lubis, dan Abd. Rahim Lubis, 2010, Hukum Pendaftaran Tanah, Jakarta: Mandar Maju.

Yamin Lubis, dan Abd. Rahim Lubis, 2010, Hukum Pendaftaran Tanah, Jakarta: Mandar Maju.

Undang-Undang dan Peraturan

Peraturan Menteri Agraria Dan Tata Ruang/Kepala Badan Pertanahan Nasional Republik Indonesia Nomor 6 Tahun $2018 \quad$ Tentang Percepatan Pendaftaran Tanah Sistematis Lengkap.

Peraturan Menteri Agraria Dan Tata Ruang/Kepala Badan Pertanahan Nasional Republik Indonesia Nomor 6 Tahun $2018 \quad$ Tentang Percepatan Pendaftaran Tanah Sistematis Lengkap.

Peraturan Pemerintah Nomor 24 Tahun 1997. Pendaftaran Tanah

Peraturan Pemerintah Nomor 24 Tahun 1997. Pendaftaran Tanah

Undang-Undang Nomor 5 Tahun 1960 tentang Peraturan Dasar Pokok-Pokok Agraria.

Undang-Undang Nomor 5 Tahun 1960 tentang Peraturan Dasar Pokok-Pokok Agraria. 